\title{
Virtual and Augmented Reality in school context: A literature review
}

\author{
Yassine BRIJ $^{1^{*}}$ and Prof. Hicham Belhadaoui ${ }^{2}$. \\ ${ }^{1}$ R.I.T.M laboratory, computer engineering department, E.N.S.E.M, Casablanca, Morocco \\ 2 R.I.T.M laboratory, computer engineering department, E.N.S.E.M, Casablanca, Morocco
}

\begin{abstract}
Virtual and Augmented reality has established itself in many sectors including education. The virtual is progressively entering the classrooms. MOOCs (Massive Open Online Course), those online interactive lessons available for all, are useful tools to complete the traditional school system. There are also more and more e-learning platforms that propose online lessons and follow-up for any student. Immersive contents appear as playful alternatives to traditional lectures. But, the integration of VR/AR equipment in classrooms raises questions. What is the place of augmented and virtual reality in education and teaching? In order to be able to answer this important question, our article takes place as the result of a literature review on the field of virtual and augmented reality in education. Our objective, first of all, to deepen our knowledge domain in order to provide the necessary answers to «the question », and, secondly, to identify principles that can guide the design of educational artefacts in virtual and augmented reality. The methodology of the literature review is based on the EPPI method (Evidence for Policy and Practice Information and Coordinating). Results will be presented by themes such as motivation, immersion, collaboration, and design.
\end{abstract}

\section{Introduction}

This literature review aims to assess the state of the current situation in the field of knowledge of virtual reality (VR) and augmented (AR) in education. The results will help to deepen knowledge and articulate guidelines to support the development of future research projects involving the design of custom software to promote the learning of primary and secondary students. In order to facilitate the reading of the document, we present a summary of the information collected by topic. The information with the authors of the texts is grouped together to then be analyzed.

To do this, we will follow an iterative path to answer our initial question of research by identifying oppositions and validations, concepts and paradigms of the field to through selected writings.

We continue with a summary of the limits and advantages noted in the reference texts, to then set out a position regarding the relevance of virtual and augmented reality as a educational tool, while taking into account the disadvantages and controversies that the use of news technologies arouses in education.

We end this work with reflective comments and possible follow-up to this review of literature.

\section{Problematic}

Although virtual reality (VR) and augmented reality (AR) are increasingly in vogue, it is allowed to challenge their relevance in the school context. It is therefore advisable to carry out a review of literature to provide guidelines based on scientific evidence.

But what is the difference between VR and AR? According to Alexander et al. (2019), Altinpulluk 2019) and Fernandez (2017), VR is immersive and allows a learner to use a helmet in particular autonomous which interacts with a completely artificial universe constructed by computer, while AR is also serving as a headset or smartphone to overlay images, text or other virtual objects to real world content.

Virtual technologies are not new; Chartier (1995) indicates that in 1968 Ivan Sutherland from Harvard University developed one of the first computing devices that used a headset as peripheral. The set allowed the user to enter a world produced by a computer. According to Chartier (1995), virtual architectures generally consist of three elements:

A sophisticated imaging system capable of creating three-dimensional objects and their give a real appearance of a control system capable of simulating the behavior of these objects and a human-machine interface allowing interaction with these objects (p. 4041).

Subsequently, several devices appeared, in particular the first optical glove, the Data Glove, invented by Thomas Zimmerman in 1982; this optical glove allows the computer system to capture human hand movements (Lowood, 2019).

Duelach, Mavor and National Research Council (1995) indicate several issues before democratization virtual technologies, especially the fact that the hardware is

\footnotetext{
* Corresponding author: brij.yassine@gmail.com
} 
expensive and not very available. However, the recent advances make them more accessible, including technological maturity and the availability of VR equipment, including the release of the Oculus Rift and HTC Vive consumer standalone headsets head-mounted display (HMD) type in 2016 (Jégou and Pallamin, 2017).

Blevins (2018) and Cook et al. (2019) indicate that studies on immersive virtual technologies in are still in their infancy and offer many possibilities in education, especially from the cognitive point of view. According to Blevins (2018) and Wang et al. (2018), the feeling of immersion in AR is similar to that that we perceive in our daily reality, because AR uses an interface to nest from computer-generated objects to the real world, while the design of a VR artifact is fully digital, allowing for a greater sense of immersion.

However, according to Garzón, Pavón and Baldiris (2019), the appropriate material for a good immersion, especially the HMD helmet, remains expensive for schools.

In this context, our research question takes the following form:

Is the use of educational artifacts in virtual and augmented reality relevant for students in a school context? If so, what are the principles that can guide their design?

\section{Methodology of the literature review}

The methodology is divided into two stages. First, we carry out a review of the writings according to the Evidence for Policy and Practice Information and Coordinating research methodology (EPPICenter, 2010) 1. This method makes it possible to identify as closely as possible the relevant articles linked to our research question and employ clear methods to identify and represent faithfully the facts described in these studies. Second, we present the synthesis of the information collected by topic. We will be able to present the results and eventually propose guidelines that can help with the use and design of educational artefacts in VR and AR in a school context.

1 Retrieved from the EPPI-Center website: https://eppi.ioe.ac.uk/cms/

Table 1. Adaptation of the stages of the EPPI review process

\section{Define the research question}

2. Choose the relevant databases

3. Choose the descriptors (thesaurus terms) for each database

4. Define the insertion criteria

5. Perform systematic research

\section{Import the results}

\section{Briefly analyze and choose the selected articles}

\section{The article selection methodology}

First, we selected six databases appropriate to the research question (combining articles in virtual and augmented technology in schools). then, we have performed the search using the descriptive operators selected for each database (see table 2). Articles must be available in English or French. A total number of 2350 articles without duplicates were recovered.

Table 2. Number of articles listed from the databases identified and the descriptors used

\begin{tabular}{|l|l|c|}
\hline \multicolumn{1}{|c|}{ Database } & $\begin{array}{l}\text { Descriptive operators of the thesaurus } \\
\text { used }\end{array}$ & Nbr of articles \\
\hline HAL Archives-ouvertes.fr & $\begin{array}{l}\text { Réalité virtuelle or réalité augmentée or augmented } \\
\text { virtual or virtual reality }\end{array}$ & 76 \\
\hline Academic Search Ultimate & $\begin{array}{l}\text { virtual reality or augmented reality and education } \\
\text { and learning }\end{array}$ & 216 \\
\hline CAIRN & $\begin{array}{l}\text { Réalité virtuelle or réalité augmentée or virtual } \\
\text { reality or vr or augmented reality and education and } \\
\text { apprentissage or learning }\end{array}$ & 756 \\
\hline ERIC & $\begin{array}{l}\text { virtual reality or augmented reality and education } \\
\text { and learning }\end{array}$ & 317 \\
\hline Educational source & $\begin{array}{l}\text { virtual reality or augmented reality and education } \\
\text { and learning }\end{array}$ & $\mathbf{2 3 5 0}$ \\
\hline $\begin{array}{l}\text { Computers and applied } \\
\text { Sciences Complete }\end{array}$ & $\begin{array}{l}\text { virtual reality or augmented reality and education } \\
\text { and learning }\end{array}$ & \\
\hline Total &
\end{tabular}

The corpus of 2350 articles has been reduced and corresponds to the three inclusion criteria identified in Table 3. First, we limit the review to studies published from 2017 onwards. The year 2017 was chosen, since recent advances in the field of immersive technologies, especially HMD helmets that allow freedom of movement, are accessible financially since 2016 . These are important elements that can affect the results (Cook $\&$ al., 2019). Second, we also limit the review to searches in context academic that are peer reviewed and include references. Finally, we let us retain that the articles related to the pupils in school context and their conception. For the last criterion, we selected the studies by reading the titles and abstracts. The total number of articles in the journal is thus limited to 29.

Table 3. Number of articles selected after using each exclusion criterion 


\begin{tabular}{|l|c|}
\hline \multicolumn{1}{|c|}{ Insertion criteria } & Nbr of selected articles \\
\hline Year of publication (2017-2020) & 1011 \\
\hline $\begin{array}{l}\text { Peer-reviewed academic journal, } \\
\text { with references }\end{array}$ & 188 \\
\hline $\begin{array}{l}\text { Specific in school context or } \\
\text { design }\end{array}$ & 29 \\
\hline
\end{tabular}

Note: For example, 832 of 1011 papers are not peer reviewed articles.

The majority of the articles selected come from the United States (9) (see Table 4).

Table 4. Mapping of selected studies

\begin{tabular}{|c|c|}
\hline Country & Occurrence \\
\hline United States & 9 \\
\hline Taiwan & 4 \\
\hline Turkey & 4 \\
\hline France & 3 \\
\hline Australia & 1 \\
\hline Canada & 1 \\
\hline Cyprus & 1 \\
\hline Colombia & 1 \\
\hline Danemark & 1 \\
\hline Spain & 1 \\
\hline Greece & 1 \\
\hline Malaysia & 1 \\
\hline United Kingdom & 1 \\
\hline
\end{tabular}

\section{Results}

All of the selected articles on VR and AR technologies in education focused on mainly on three important dimensions related to knowledge transfer: motivation, immersion and cooperation. We have also kept the articles that address the design educational virtual artifacts. In addition, we refer to previous studies to support the theories and concepts presented therein. It seemed relevant to us at first to group the studies by topic, then describe the advantages and disadvantages of the educational artefacts in VR and AR.

\section{Motivation}

Motivation is a factor that influences attention, an important cognitive function in the process knowledge transfer (Long, Wood, Littleton, Passenger \& Sheehy, 2011). The theme of the motivation appeared in eighteen selected articles (18/29).

The majority of authors cite the positive impact of VR and AR technologies on motivation. Altinpulluk (2019) also indicates that the main advantages of VR and AR technology in education is about improving student achievement and motivation. Motivation improves attention, which is an essential cognitive function for learning. Educational artefacts, especially serious games, have a positive influence on motivation and the awakening of learning. Among others, several games are designed according to the level of the player; the level of difficulty is automatically adjusted according to results, which improves motivation and persistence. Improved motivation is linked mainly with two axes for the player, that is to keep what he has done during the game and that share it with their peers (Mildner, Stamer and Effelsberg, 2015). Redondo, Cózar-Gutiérrez, González-Calero and Sánchez Ruiz (2020) also mention that AR significantly increases motivation students as well as the pleasure of learning.

Cook \& al. (2019) indicate that recent studies demonstrate that while educational artefacts are developed according to the rules of the art, they are effective, motivating and have the advantage of being reusable. Artifacts in VR and AR have benefits for learners, including motivation, concentration and visualization of concepts (Edwards, Bielawski, Prada and Cheok, 2019; Garzón et al.,2019). The aspects studied by Veermans and Jaakkola (2019) indicate that the transfer of skills is faster when the learner learns by trial and error during manipulation, instead of following a formal process with detailed instructions. According to Cooper, Park, Nasr, Thong and Johnson (2019), it is motivating for students to have the opportunity to explore distant places and phenomena abstract and complex in science. Abdusselam, Kilis, Şahin Çakır and Abdusselam (2018) mention that AR improves interpretation of observations, develops science skills and positive attitudes. For their part, Cooper \& al. (2019) indicate that the potential for student engagement is increased with the use of virtual technologies. According to Cooper \& al. (2019), VR environments can be motivating for students, leading them to spend more time on the educational task, and offer a better learning experience. According to Demitriadou, Stavroulia and Lanitis (2020), VR technology improves students spatial skills and knowledge transmission. On the other hand, Chang, Debra Chena and Chang (2019) note that the use of an educational artifact in VR can increase workload or teaching time. So as not to reduce the interest of teachers in using new technologies, schools have an advantage in offering adequate support teachers (Chang \& al., 2019).

Liou, Yang, Chen and Wernhuar (2017), Garzón et al. (2019) and Chen, Smith, York and Mayall (2020) indicate that $\mathrm{VR}$ and $\mathrm{AR}$ technologies improve learning motivation, but also encourage students to persevere. In addition, Che Hashim, Abd Majid, Arshad and Khalid Obeidy (2018) mention that an application that is easy to use increases student motivation and the transfer of knowledge. Herbert, Ens, Weerasinghe, Billighurst and Wigley (2018) and Makransky, Borre-Gude and Mayer (2019) claim that VR has a positive impact on learner motivation, however, according to them, it does not present a marked advantage on the retention of skills. 


\section{The immersion}

Six studies (6/29) looked at the sense of immersion created by virtual artefacts. We define VR immersion, whether physical or psychological, as being what "allows the introduction into the person of the belief that they have left the real world and that they are now present in the virtual environment " (" Immersion / Présence ", 2019, p. 1).

Jensen and Konradsen (2018) mention that new mobile devices provide an experience beneficial immersive in education. The increased immersion offered by new VR technology, especially with HMD helmets, seems well suited to constructivist pedagogical approaches and simulation-based learning. What is more, Edwards et al. (2019) claim that VR incorporates multiple benefits, including immersion, as well as multisensory and tactile learning. According to Edwards et al. (2019), the immersive VR environment improves understanding of abstract concepts, promotes student engagement, motivation and interest.

According to Cook \& al. (2019), virtual reality is still an immature technology. Technically superior consumer HMD headsets became widely available in 2016 with the release of the Oculus Rift and HTC Vive systems. Learners recognized the immersive potential of VR technology; VR technology offers students the opportunity to explore remote places and view abstract universes / environments such as manipulating atoms (Garzon et al., 2019; Cooper et al., 2019). In contrast, Cook \& al. (2019) mention that several learners revealed having experienced a Cybermalaise, without forgetting that, for many participants, mastering interfaces is complex.

Cyber kinetosis, or "cybersickness," has been observed in motion sickness studies in relation to flight simulators (Durlach \& al., 1995). Leung and Hon (2019) indicate that the Cyber kinetosis is a common problem in virtual reality. According to Leung and Hon (2019), it manifests during "sensory conflict and neural shift". Cyber kinetosis is mainly manifested by nausea, headache, dizziness, spatial disorientation and dizziness (Leung et al. Hon, 2019).

Hite \& al. (2019) mention that some students are cognitively incapable of thinking operational. Concrete operational thinking is the third step of Piaget's theory cognitive development (1964/2003). According to the latter, it manifests itself between 7 and 11 years old and corresponds to the appropriate use of logic, as the student begins to solve the problems in a more logical way. However, Piaget (1964/2003) mentions that there may be a lag, some children reaching a late stage of development. On the other hand, Sol Roo (2017), Ucar, Ustunel, Civelek and Umut (2017) and Yoon, Anderson, Lin and Elinich (2017) indicate that the gradual increase in immersion with VR technology can create mental models correct for students, especially when developing objects that tell stories. On the other hand, Blevins (2018) and Jensen and Konradsen (2018) indicate that studies on technologies immersive virtual systems are still in their infancy and the limited number of studies indicates the need further research on HMD helmets in educational settings. As Jense and Konradsen (2018) indicate, HMD headsets can be used as an interface for learning to several skills, but they do not always have an added value compared to the methods traditional. Plus, they can be counterproductive, because the immersive experience distracts you. Finally, Kenwright (2018) mentions that VR artifacts also have the power to induce significant physiological trauma. According to Ramirez and LaBarge (2018), VR is the most immersive in the market and allows the user to live experiences that he cannot differentiate from the reality, which they call "near real experience". 3D VR technology can recreate artificially close to reality universes, using techniques that reproduce the effects of depth of field and techniques that faithfully reproduce the colors and sounds present in reality. The avenue of HMD helmets allows the user to be removed from any external element and increases immersion, which could lead to behavioral changes in the individual caused by changes of a psychological or neurological nature.

\section{The collaboration}

Twelve selected articles (12/29) address the topic of collaboration and interaction in reality Virtual. Altinpulluk (2019) indicates that VR enables interaction and collaboration, provides a space for creation and improves kinesthetic, visual and spatial skills. Lee and Shea (2020) report that dialogue allows learners to broaden their understanding through interaction with the others. In addition, according to Sol Roo (2017), VR learning environments have the potential to enable students to solve problems as a team anywhere on the planet. Demitriadou et al. (2019) reveal that VR and AR technologies are more interactive and interesting for students than the use of conventional materials, since they allow learners to deepen their knowledge by trying to solve and explore a problem as a team. Cooper \& al. (2019) add that collaborative virtual environments (CVE) allow interaction between students, teachers and digital content. Sol Roo (2017) highlights the benefits of collaboration in VR, especially when an expert explains to a distance learner how to perform complex manipulations. Harvard (2018) adds that AR allows a user to communicate in real time with a remote expert. The technology thus responds to a need to share knowledge and collaboration. In addition, Billingsley, Smith, Smith and Meritt (2019) state that the VR and RA technology allows remote control and feedback. According to Pellas, Fotaris, Kazanidis and Wells (2019), the educational potential of AR technology is significant, since it influences the cognitive abilities of students. Redondo et al. (2020) also mention that AR improves student interaction in the classroom. Pellas et al. (2019) add that AR technology improves students' metacognitive process and their engagement in activities based on practical, in particular by bringing to life invisible, abstract and complex concepts. According to Redondo et al. (2019), the interaction creates a special atmosphere in which students improve their socioemotional relationships, through cooperation and respect. Finally, the use of AR in class increases the 
desire to play and share with other students (Redondo et al., 2019).

\section{The Design}

Five articles (5/29) deal with the design of educational virtual 3D environments. Authors provide recommendations for hardware and applications. To begin with, let's present the many peripherals used in virtual technology and continue with the description of the main recommendations for application designers.

There are three types of interfaces in VR : the fixed screen on a computer, smart phones and tablets, and finally, HMD headsets (Cook \& al., 2019; Wang \& al., 2018). According to Wang \& al. (2018), headsets designed for VR are different from those for AR, since the latter superimpose unreal elements on very real environments. Cook \& al. (2019) mention that the use of HMD headsets and the possibility of using a variety of applications are an advantage interesting for the world of education. The study by Ucar \& al. (2017) states that a haptic device in 3D, which offers "six degrees of freedom", improves knowledge transfer.

Six degrees of freedom $(6 \mathrm{DoF})$, refer to the freedom of movement of a rigid body in a three-dimensional space. More precisely, the body is free to change position by forward / backward, up / down and left / right transition, combined with three-axis rotation perpendicular (normal, transverse and longitudinal).

Free translation of "Six degrees of freedom" (2020)

Abdusselam \& al. (2018) add that virtual technology is interesting, especially in education.The HMD helmet with virtual and immersive 3D applications in the fields of chemistry and physics is already used in secondary schools (Andone and Frydenberg, 2019). However, Cooper \& al. (2019) mention that educational VR applications vary in quality. Furthermore, several articles indicate that the main limitation of virtual educational technologies is linked to the educational systems design (Hite \& al., 2019; Ibili, 2019; Jensen and Konradsen, 2018; Lee and Shea, 2020; Yeh, Lan and Lin, 2018). In this context, designers of virtual technology must integrate the characteristics that influence learning, especially to support collaboration and knowledge-based engagement, and enable the coconstruction of knowledge (Pellas et al.,2019). For Cooper \& al. (2019), content is crucial, and without well-designed content that improves the long-term knowledge transfer, virtual technologies have no interest in education. Vallera (2019) adds that VR technologies must increase the understanding of complex subjects and demonstrate better retention of information. Without forgetting that to promote the pleasure of learning, it is necessary to take into account the theory of "flow" of Csikszentmihalyi (1990). According to this theory, for teaching tasks to remain a fun and motivating activity, they must offer an experience which he calls "flow". He describes it as an activity which in itself brings a sense of satisfaction and immersion. As mentioned by Edwards \& al. (2019), we must generate commitment cognitive and positively influence the emotional engagement of the student, in particular through the gamification of learning.

Chang, Hsu, Wu and Tsai (2018) and Sauvé (2010) mention the importance of designing tasks learning with appropriate levels of difficulty and emphasizing the importance of splitting the content, gradually incorporating the level of exercises. The research of Moreno (2006) on cognitive strategies come to the same conclusion, namely that when one start learning a new field, it is difficult to regularize the flow of news knowledge. In addition, Yeh \& al. (2018) and Bates (2017) indicate that the virtual environment must be designed according to the target audience, including taking into account gender differences and needs specific learning.

Ba e\& al. (2019) add that new educational technologies must be designed to improve creative and research activities in the field of science. However, it is essential involve faculty in the design of the artifacts so that they can incorporate the material classroom instruction (Ba \& al., 2019; Chang \& al., 2019; Cooper \& al., 2019). According to Bates (2017), educational tools should be designed as close as possible to reality, which improves cognition learners and thereby provides effective learning. Wang \& al. (2018) add that the use of AR technologies reduces training time to master certain tasks. On the other hand, it is essential that the scenario and the design of the artifact are well suited to the skills criticisms that we want to transfer to the learner.

Liou \& al. (2017) mention that AR applications offer better educational performance than VR applications, since they integrate virtual objects and real environments in order to reduce the learner's mental load. According to Maas and Hughes (2020), the rapid progress of technology and the reduction in their cost facilitate its integration into the school environment. However, access to virtual content remains a constraint due to the computing capacity of computers available in most schools, Kindergarten to Grade 12. Cook \& al. (2019) and Hite \& al. (2019) add that one of the main challenges of this type of learning technology is the high cost the design and construction of virtual environments. According to Kenwright (2018), new VR applications can be innovative in education. On the other hand, Kenwright (2018) lists the risks, particularly on the health of young children in the short term and long-term as well as on ethical issues. Ramirez and LaBarge (2018) indicate that VR offers the opportunity to live experiences that are very close to reality, which leads to ethical problems. Ramirez and LaBarge (2018) argue that users should not be given experiences that are bad in reality in VR. According to Ramirez and LaBarge (2018), being in a world virtual should not fuel certain unhealthy social impulses, including sexism and racism. Finally, Casarin (2019) and Kenwright (2018) recommend that designers perform tests investigation and analysis before commissioning. In addition, Casarin (2019) presents a series of tools with measures of performance indicators and statistical analysis allowing the evaluation of virtual artifacts.

\section{Advantages}


According to Ba \& al. (2019), VR and AR are seen by experts as technologies of the future in education, these authors draw on several studies in the field of science. We have listed the main identified benefits of these technologies in the selected articles. Let's present them by grouping them with the main authors who tackle the subjects:

- allows objects to be handled in dangerous environments in a safe manner (Abdusselam \& al., 2018; Altinpulluk, 2019; Bates, 2017; Cooper \& al., 2019; Chen, Zhang, Luczak, Smith \& Burch, 2019; Jensen and Konradsen, 2018; Makransky \&al., 2019; Ucar \& al., 2017; Wang \& al., 2018);

- reduces training costs in several areas of study, including the use of chemistry and biology laboratories, which require significant investments and which carry risks for learners and the environment (Cook \& al., 2019; Cooper \&al., 2019; Pelas \& al., 2019; Ucar \& al., 2017);

- offers the possibility of visiting distant geographical sites and discovering universes that are not accessible (Altinpulluk, 2019; Bates, 2017);

- $\quad$ increases the possibility for learners to control their learning and provides a sensory engagement similar to a child's natural learning process (Abdusselam \& al., 2018; Altinpulluk, 2019; Garzón \& al., 2019);

- improves spatial acuity, creativity and the metacognitive process of students (Blakesley, 018; Demitriadou \& al., 2020; Hite \& al., 2019);

- offers the possibility of communicating remotely in real time with an expert; more devices are wearable devices, especially HMD headsets, present an innovative opportunity for the medical and educational field (Billingsley \& al., 2019; Cooper \& al., 2019; Edwards \& al., 2019; Harvard, 2018; Maas and Hughes, 2020);

- promotes motivation, commitment and knowledge transfer (Abdusselam \& al., 2018; Altinpulluk, 2019; Andone and Frydenberg, 2019; Bates, 2017; Che Hashim \& al., 2018; Cooper \& al., 2019; Makransky \& al., 2019; Redondo \& al., 2020; Ucar \& al., 2017; Wang \& al., 2018);

- facilitates interaction and improves collaboration between learners and teachers (Billingsley \& al., 2019; Demitriadou \& al., 2020; Ibili, 2019; Lee and Shea, 2020; Redondo \& al., 2020);

- reduces foreign cognitive load, improves working memory and information retention (Lacko, 2019; Vallera, 2019; Yoon \& al., 2017);

- improves understanding of abstract and complex phenomena, especially with haptic applications during manipulations in laboratories (Pelas \& al., 2019; Sol Roo, 2017;
Vallera, 2019; Ucar \& al., 017; Yoon \& al., 2017).

\section{Limits}

While not perfect, we have listed the main limitations of VR and AR identified in the selected items. We present them by grouping them with the main authors who discuss the subjects:

- requires significant financial investments for the implementation of the technology and training of staff in educational institutions (Cook \& al., 2019; Cooper \& al., 2019; Garzón \& al., 2019; Hite \& al., 2019; Lee and Shea, 2020; Maas and Hughes, 2020; Pelas \& al., 2019; Reynard, 2017; Redondo \& al., 2020);

- no exhaustive study on the performance of VR for the acquisition of knowledge practices and knowledge retention (Herbert \& al., 2018; Lanier \& al., 2019; Makransky \& al., 2019);

- $\quad$ cybersecurity and ethical issues that need to be addressed. (Cooper \& al., 2019; Jensen and Konradsen, 2018; Kenwright, 2018);

- non-compliant, poorly designed applications and poor teacher training (Hite \& al., 2019; Ibili, 2019; Lee and Shea, 2020; Reynard, 2017; Yeh \& al., 2018);

- insufficient research to investigate the repercussions of VR in psychological, especially on young children (Cook \& al., 2019; Herbert \& al., 2018; Ibili, 2019; Kenwright, 2018);

- possible physiological trauma and behavioral changes in the individual caused by changes of a psychological or neurological nature (Kenwright, 2018; Ramirez \& LaBarge, 2018);

- additional cognitive load of the media for the learner (Altinpulluk, 2019; Chang \& al., 2018; Cook \& al., 2019; Jensen and Konradsen, 2018; Makransky \& al., 2019);

- the lack of social acceptability of immersive technologies (Tham, McGrath, Duin and Moses, 2018);

- The distraction, time to use and integrate technology is too long (Chen \& al., 2020);

- the development of educational applications can be quite complex and expensive (Cook \& al., 2019; Hite \& al., 2019);

- the possibility of suffering from cyberthreat, especially when using HMD headsets in VR. Symptoms are similar to motion sickness, including nausea and difficulty respiratory tract (Casarin, 2019; Cook \& al., 2019; Kenwright, 2018; Somrak \& al., 2019).

\section{Discussion and reflective comments}

According to the literature review, educational artefacts designed in virtual reality and augmented reality can 
improve attention and cognition. However, for them to be effective, they must include no only instructional methods adapted to the target audiences, but also use an appropriate medium for the area of knowledge of the targeted training. We agree with the conclusion of Moreno (2006): the method used and the choice of media must be consistent, since the two elements to complement each other. Veermans and Jaakkola (2019) indicate that more focus should be on design artefacts, to find a balance between the pleasure of handling the tool and its ability to transfer knowledge. Altinpulluk (2019) adds that VR enables interaction and collaboration, provides space creation and improves kinesthetic, visual and spatial skills. Unfortunately, current technologies limit the use of VR, not to mention the associated costs the integration of the material and the few applications in the school context. Let us add that their acceptabilities social are weak, both with teachers and parents.

In addition, we wonder about the dangers associated with virtual reality. According to Ramirez and LaBarge (2018) and Kenwright (2018), VR could lead to behavioral changes in the individual, caused by changes of a psychological or neurological nature. Without forgetting the risk of experiencing a cybermalaise (Kenwight, 2018; Somrak \& al., 2019). The scarcity of studies on the risks that can subject immersive technologies, particularly to young children (Herbert \& al., 2018; Ibili, 2019; Kenwright, 2018), urges us to be cautious. To minimize the risks associated with applications immersive, their introduction in schools must be done gradually and be reviewed periodically according to the results of the investigative and analytical tests that were incorporated during their creation (Kenwright, 2018).

We also emphasize the importance of accelerating research on the phenomena that influence users of virtual technologies and thus allow designers to produce artefacts safer and better adapted to users.

This report improves our knowledge of the design of several essential elements that influence the effectiveness of an educational artefact in VR and AR, in particular to set up a medium that takes into account the cognitive load of the target audience, the disadvantages associated with the use of artefacts immersive and the importance of the theory of "flow" by integrating the playful dimension and the consistently serious (Csikszentmihalyi, 1990).

Finally, the design of virtual applications becomes more complex when it comes to working with technologies that are not yet available. As Blevins (2018) mentions, it will be necessary to be visionary, grasping the future and being flexible throughout the design process to perform the necessary modifications.

\section{Conclusion}

The goal of a virtual learning system is to achieve educational goals through the transfer of new knowledge and skills. Media and methods must align to form a user-friendly whole and be adapted to the targeted skills. According to Bates (2017), Moreno (2006), Sauvé (2010) and Wang \& al. (2018), it is essential that the scenario and the design of the artifact are well suited to the critical skills that we want to transfer to the learner.

Above all, we must not forget that educational technologies are tools at the service of humans and that their design must above all be based on motivational theories as well as on educational theories in order to meet the educational objectives of the training. What we have discovered, is that the majority of studies that have been carried out on the subject, confirm that if the artefacts educational programs are well designed, they are useful for learning (Altinpulluk, 2019, Andone and Frydenberg, 2019, Blakesley, 2018, Makransky \& al., 2019). However, they must be created taking into account the interests and abilities of students. Fernandez (2017) mentions that the main objective in education is to improve the transfer of knowledge to learners and not to promote a tool. The system education must offer the best tools and programs to achieve this goal (Fernandez, 2017).

Finally, it is also important to consider the risks associated with VR. According to Kenwright (2018) and Ramirez and LaBarge (2018), VR could lead to behavioral changes in the individual caused by changes of a psychological or neurological nature. As for them, Jensen and Konradsen (2018) and Somrak \& al. (2019) point out the risks in VR of experiencing side effects, the "Cybermalaise".

This work made it possible to identify the probable educational advantages of virtual technologies and their limits. However, we must remain cautious, given the risks of abuse or misuse, or even the risks of a design that is not suitable for students. It is essential that further research be undertaken to assess the risks associated with the misuse of technology. As Bates (2017) and Jensen and Konradsen (2018) point out, studies in the area of knowledge virtual educational technologies need to increase.

\section{References}

[1] Alexander, B., Ashford-Rowe, K., Barajas-Murphy, N., Dobbin, G., Knott, J., McCormack, M., Pomerantz, J., Seilhamer, R.et Weber, N. (2019). EDUCAUSE Horizon Report: 2019. Higher Education Edition. Louisville, CO:

EDUCAUSE.https://library.educause.edu/media/file s/library/2019/4/2019horizonreport.pdf?la=en\&has $\mathrm{h}=$ C8E8D444AF372E705FA1BF9D4FF0DD4CC6F0 FDD1

[2] Andone, D. et Frydenberg, M. (2019). Creating virtual reality in a business and technology education 
context. Dans Tom Dieck, M. C. et Jung, T. (dir.), Augmented reality and virtual reality (p. 147-159). Switzerland, Springer Nature.

[3] Ba, R., Xie, Y., Zhang, Y., Faatihah Binte Mohd Taib, S., Cai, Y., Walker, Z., Chen, Z., Tan, S., Hoe Chow, B., Min Lim,S., Pang, D., Lin Goei, S., Matimba, H. E. K. et van Joolingen, W. (2019). Virtual reality enzymes: an interdisciplinary and international project towards an inquiry-based pedagogy. Dans Cai, Y., van Joolingen, W. et Walker. Z. (dir.), VR, simulations and serious games for education (p. 45-54). [4] Singapore, Springer Nature.Casarin, J. (2019). Proposition d'un protocole web pour la collaboration multi-support en environnement 3D : UMI3D. Web. Université de Strasbourg, 2019. Français.

https://tel.archives-ouvertes.fr/tel02518604/document

[5] Chang, C.-Y., Debra Chena, C.-L. et Chang, W.-K. (2019). Research on immersion for learning using virtual reality,augmented reality and mixed reality. Presses Universitaires de France « Enfance ». 2019(3), 413-426. https://doi.org/10.3917/enf2.193.0413 [6] Chang, H.-Y., Hsu, Y.-S., Wu K.-H. et Tsai, C.-C. (2020). Students' development of socio-scientific reasoning in a mobile augmented reality learning environment. International Journal of Science Education, 40(12), 1410-1431.

https://doi.org/10.1080/09500693.2018.1480075 [7] Chen, Y., Smith, T. J., York, C. S. et Mayall, H. J. (2021). Google Earth Virtual Reality and expository writing for young English Learners from a Funds of Knowledge perspective. Computer Assisted Language Learning, 33(1/2), 1-25.

https://doi.org/10.1080/09588221.2018.1544151

[8] Cook, M., Lischer-Katz, Z., Hall, N., Hardesty, J., Johnson, J., McDonald, R. et Carlisle, T. (2019).

Challenges and Strategies for Educational Virtual Reality: Results of an Expert-led Forum on 3D/VR Technologies across Academic Institutions. Information Technology \& Libraries, 38(4), 25-48. https://doi.org/10.6017/ITAL.V38I4.11075 [9] Cooper, G., Park, H., Nasr, Z., Thong, L.-P. et Johnson, R. (2020). Using virtual reality in the classroom: preservice teachers' perceptions of its use as a teaching and learning tool. Educational Media International, 56(1), 1-13.

https://doi.org/10.1080/09523987.2019.1583461 [10] Demitriadou, E., Stavroulia, K.-E. et Lanitis, A. (2021). Comparative evaluation of virtual and augmented reality for teaching mathematics in primary education. Education \& Information Technologies, 25(1), 381-401. https://doi.org/10.1007/s10639-01909973-5

[11] Durlach, N. I., Mavor, A. S., et National Research Council (États-Unis). (1995). Réalité virtuelle : défis scientifiques et technologiques. Presse des académies nationales.

[12] Edwards, B. I., Bielawski, K. S., Prada, R., et Cheok, A. D. (2020). Haptic virtual reality and immersive learning for enhanced organic chemistry instruction. Virtual Reality, 23(4), 363-373.

https://doi.org/10.1007/s10055-018-0345-4
[13] Hite, R. L., Jones, M. G., Childers, G. M., Ennes, M., Chesnutt, K., Pereyra, M. et Cayton, E. (2019). Investigating Potential Relationships Between Adolescents Cognitive Development and Perceptions of Presence in 3-D, Haptic-Enabled, Virtual Reality Science Instruction. Journal of Science Education \& Technology, 28(3), 265-284.

https://doi.org/10.1007/s10956-018-9764-y

[14] İbili, E. (2019). Effect of augmented reality environments on cognitive load: pedagogical effect, instructional design, motivation and interaction interfaces. International Journal of Progressive Education, 15(5), 42-57.

https://doi.org/10.29329/iipe.2019.212.4

[15] Immersion / Présence. (2019). Laboratoire de Cyberpsychologie de l'UQO.

http://w3.uqo.ca/cyberpsy/index.php/immersion-etpresence/

[16] Lee, C. K. et Shea, M. (2020). Exploring the use of virtual reality by pre-service elementary teachers for teaching science in the elementary classroom. Journal of Research on Technology in Education, 52(2), 163177. https://doi.org/10.1080/15391523.2020.1726234

[17] Leung, A. K. et Hon, K. L. (2019, décembre). Motion sickness: an overview. Drugs in context. https://doi.org/10.7573/dic.2019-9-4

[18] Lowood, H. E. (2019). Virtual reality. Dans Encyclopædia Britannica. Récupéré le 28 mai 2020 du site

https://www.britannica.com/technology/virtualreality

[19] Maas, M. J. et Hughes, J. M. (2010). Virtual, augmented and mixed reality in $\mathrm{K}-12$ education: a review of the literature.Technology, Pedagogy \& Education, 29(2), 231-249.

https://doi.org/10.1080/1475939X.2020.1737210 [20] Six degrees of freedom. (2021, 11 avril). Dans Wikipédia.

https://en.wikipedia.org/w/index.php?title=Six degr ees of freedom\&oldid $=950326946$

[21] Sol Roo, J. (2017). One reality: augmenting the human experience through the combination of physical and digital worlds[thèse de doctorat, Université de Bordeaux, France]. https://tel.archivesouvertes.fr/tel-01702720

[22] Somrak, A., Humar, I., Hossain, M. S., Alhamid, M.F., Hossain, M. A. et Guna, J. (2019). Estimating VR sickness and user experience using different HMD technologies: An evaluating study. Future Generation Computer Systems, 2019(94), 302-316.

https://doi.org/10.1016/j.future.2018.11.041 [23] Abdusselam, M. S., Kilis, S., Şahin Çakır, Ç., et Abdusselam, Z. (2018). Examining Microscopic Organisms underAugmented Reality Microscope: A 5E Learning Model Lesson. Science Activities, 55(1/2), 68-74.

[24] François Lewis, Patrick Plante and Daniel Lemire (2021). Relevance, effectiveness, and pedagogical principles of virtual and augmented reality in school context.

https://www.researchgate.net/publication/34890997 9 Pertinence efficacite et principes pedagogiques 
de la realite virtuelle et augmentee en contexte scolaire

[25] Minjuan Wang, Vic Callaghan, Jodi Bernhardt, Kevin White and Anasol Peña-Rios (2017).

Augmented reality in education and training: pedagogical approaches and illustrative case studies. https://www.researchgate.net/publication/31830257 8 Augmented reality in education and training pedagogical approaches and illustrative case stud ies 